\title{
O USO DO JOGO NO ENSINO DE BIOLOGIA: UMA PROPOSTA LÚDICA BASEADA NO DIÁLOGO INTERCULTURAL
}

\author{
THE USE OF GAME IN BIOLOGY TEACHING: A PLAYFUL PROPOSAL BASED ON \\ INTERCULTURAL DIALOGUE
}

\author{
Emanuele Maria Leite SUZART ${ }^{*}$, Geilsa Costa Santos BAPTISTA ${ }^{2}$, Eraldo Medeiros COSTA-NETO ${ }^{3}$
}

${ }^{1}$ Programa de Pós-Graduação em Ensino, Filosofia e História das Ciências da Universidade Federal da Bahia e Universidade Estadual de Feira de Santana, Salvador, Bahia, Brasil; ${ }^{2}$ Universidade Estadual de Feira de Santana, Departamento de Educação, Feira de Santana, Bahia, Brasil; ${ }^{3}$ Universidade Estadual de Feira de Santana, Departamento de Ciências Biológicas, Feira de Santana, Bahia, Brasil. *emanuele.su@gmail.com

\begin{abstract}
RESUMO
O presente estudo tem como objetivos apresentar e sugerir um jogo, o qual foi construído a partir de uma tese sobre o conhecimento etnoentomológico de uma comunidade e o conhecimento científico escolar acerca dos insetos. Para a escrita desse trabalho, foram realizadas a leitura da tese e do conteúdo sobre insetos contidos nos livros didáticos de Biologia e, em seguida, a seleção das informações a serem utilizadas na elaboração do jogo. Nos resultados, foram apontadas as possibilidades de diálogo entre os conhecimentos científico escolar e etnoentomológico sobre os insetos. Nesse sentido, concluiu-se que uma das contribuições é a valorização da pluralidade de conhecimentos presentes na aula. Sendo assim, o recurso precisa ser aplicado na aula de Biologia das escolas da própria comunidade com o objetivo de ser validado e aprimorado.
\end{abstract}

Palavras-chave: Cultura, Conhecimento, Ensino de Ciências, Etnobiologia, Interculturalidade

\begin{abstract}
The present study aims to present and indicate a game, which was builted from a thesis about the ethnoentomological knowledge of a community and the scientific school knowledge about insects. For the writing of this work were read the thesis and substance in Biology's textbooks on insects and the information that will be used at the game elaboration. The results pointed out the possibilities of a dialogue between scientific scholarly knowledge and ethnoentomological one about insects. In this regard, it was concluded that one of the contributions is the appreciation of the variety of knowledge present in class. Therefore, the resource needs to be enforced in Biology class of the community's schools with the goal for validation and improvement.
\end{abstract}

Keywords: Culture, Ethnobiology, Interculturality, Knowledge, Science education

\section{INTRODUÇÃO}

Considerando as salas de aula como ambientes heterogêneos do ponto de vista cultural (BAPTISTA, 2010; SIQUEIRA, 2012; SILVIA; BAPTISTA, 2017), estas são permeadas por, no mínimo, duas culturas: uma, a da ciência, representada pelo conhecimento científico escolar através das disciplinas escolares, currículo, professor e materiais didáticos; outra, a dos estudantes, representada pela visão de mundo e pelos aspectos culturais do meio onde vivem (COBERN, 1996).

A ciência pode ser considerada como um fenômeno cultural, uma vez que os próprios pressupostos, critérios, vocabulário, regras e interpretação dos fenômenos são gerados a partir da interação estabelecida dentro da comunidade científica, em um determinado tempo histórico (AIKENHEAD, 2001). Esse conjunto de elementos que caracteriza a cultura da ciência constitui um conhecimento particular, o qual é denominado de conhecimento científico.

A visão de mundo dos alunos também é constituída a partir do conjunto de características, pressupostos e crenças baseadas na cultura (SEPULVEDA, 2003) em que estão inseridos. Exemplo disso é o conhecimento etnobiológico de alunos oriundos de comunidades tradicionais, como de pescadores, quilombolas, indígenas, extrativistas, entre outros (DIEGUES, 2000). Segundo Posey (1987), ele é compreendido como um conjunto de conhecimentos e conceitos produzidos por 
determinada cultura a respeito da biologia. Em outras palavras, afirma-se que esse conhecimento é a maneira como as diversas culturas interagem, percebem e interpretam o mundo biológico (ALBUQUERQUE; ALVES, 2014).

A Lei de Diretrizes e Bases da Educação Brasileira de nº 9.394/96 (BRASIL, 1996), um dos principais documentos oficiais da educação brasileira, orienta que a diversidade cultural deve ser reconhecida e valorizada no ensino escolar. Porém, o ensino das escolas brasileiras, em sua maioria, possui o foco na supervalorização dos conhecimentos científicos (LOPES, 1999). Em decorrência disso, o conhecimento cultural do aluno, sobretudo aquele denominado de etnobiológico, continua a sendo desvalorizado na sala de aula.

Isto acontece, em parte, por duas razões. A primeira refere-se ao fato de o professor conceber o seu papel em sala de aula como mero transmissor de conhecimentos científicos (RODRIGUES et al., 2010). A segunda deve-se à concepção cientificista, prevalente entre os professores, de que o conhecimento científico seria superior epistemologicamente em relação a outros sistemas de conhecimento (COBERN; LOVING, 2001; BAPTISTA, 2010; SIQUEIRA, 2012; NASCIBEM; VIVEIRO, 2015), o que objetivaria provocar a substituição dos conhecimentos dos alunos por ideias científicas, conforme a proposta de Mudança Conceitual (POSNER et al., 1982).

Diante disso, o ensino desenvolvido nas disciplinas escolares se resume em um processo de ensino-aprendizagem baseado na memorização de conhecimentos científicos distantes da realidade do aluno (COSTA, 2008; SIQUEIRA, 2011; NASCIBEM; VIVEIRO, 2015) e supervalorizados, já que são considerados como únicos conhecimentos válidos (COBERN; LOVING, 2001; BAPTISTA, 2010; BAPTISTA, 2015; NASCIBEM; VIVEIRO, 2015).

Uma possível solução para tal problemática seria estimular os professores a investigar e compreender a visão de mundo dos alunos, tendo como referência a Etnobiologia (VERDE, et al., 2009; BAPTISTA, 2010; SIQUEIRA, 2011; SIQUEIRA, 2012; BAPTISTA, 2015), através do uso de procedimentos metodológicos e/ou publicações próprias (BAPTISTA, 2014), com o intuito de valorizar esse conhecimento no ensino de Biologia, em especial.

No sentido de exemplificar algumas experiências, é possível citar, inicialmente, o estudo realizado por Baptista (2007) cujo objetivo foi investigar os resultados das aulas de ciências, durante a intervenção de uma sequência de ensino e materiais didáticos que contém tabelas de cognição comparada (MARQUES, 2001), construídas a partir das semelhanças e diferenças entre o conhecimento dos estudantes agricultores e o conteúdo de Biologia contidos nos livros didáticos. A investigação é um estudo de caso e foi desenvolvida na Escola Dom Pedro II, situada no município de Coração de Maria, Bahia.

O trabalho de Martins, Baptista e Oliveira (2016) propôs uma discussão sobre a construção de uma mapa conceitual a partir de conhecimentos compartilhados por estudantes marisqueiras da Ilha de Maré, localizada na Baía de Todos os Santos, no município de Salvador/BA, com o propósito de favorecer o dialogo intercultural entre o conteúdo de ecologia e o conhecimento das estudantes acerca da ecologia dos mariscos provenientes da atividade da mariscagem na aula de biologia.

Por fim, Silva e Baptista (2017) apresentam a construção de um jogo de tabuleiro que relaciona o conhecimento culturalmente herdado dos alunos ao conhecimento escolar sobre os fungos. No primeiro momento, o estudo consistiu em aplicar um questionário aos alunos e, a partir dos dados levantados, foram elaboradas tabelas de cognição comparativa entre o conhecimento prévio dos alunos e o biológico escolar. A proposta do jogo foi aplicada nas salas de aula, com o intuito de analisar sua validade.

Conforme foi citado anteriormente, Baptista (2014) sugere que professores de Ciências e Biologia utilizem as próprias publicações da Etnobiologia realizadas em seus contextos para a construção de propostas de intervenções, a fim de trabalhar o conhecimento cultural do aluno e o da ciência na sala de aula. Embasados nessa ideia, os autores propõem o presente trabalho.

No tocante a discussão no âmbito da área da educação científica sobre a inserção da diversidade cultural no ensino escolar de Ciências, o presente trabalho é referenciado no Pluralismo Epistemológico para argumentar que os professores demarquem os conhecimentos culturais dos alunos com relação aos conhecimentos científicos, a fim de deixar claro que cada um possui valores e critérios epistêmicos próprios e legítimos, distanciando-se, assim, de qualquer juízo de valor sobre os conhecimentos (COBERN; LOVING, 2001; BAPTISTA; DA SILVA SANTOS; COBERN, 2016).

Por fim, defende-se que o ensino de Ciência e de Biologia se baseie no diálogo intercultural entre os conhecimentos. O diálogo, ao ser instituído entre professores e alunos e entre os próprios alunos, cria espaços que oportunizam a exposição do conhecimento científico a ser ensinado e do conhecimento 
cultural dos alunos, assim como a origem, os critérios de validade e as situações de aplicação de cada um deles (BAPTISTA, 2010).

Alicerçados nessa perspectiva, os professores podem pensar em estratégias e no uso de recursos didáticos que os auxiliem no diálogo intercultural e um desses recursos pode ser o jogo.

$\mathrm{Na}$ literatura é possível encontrar diversas definições para o termo "jogo". Segundo Miranda e Stadzisz (2017), essas definições podem incorporar conceitos como brincadeira, conflito, luta, trabalho entre outros, o que deixa evidente a falta de consenso sobre o termo entre os pesquisadores e a comunidades de jogos.

No presente trabalho, o termo "jogo" será considerado como um componente da cultura humana (HUIZINGA, 2000), em virtude da sua relevância para "[...] o desenvolvimento social, cognitivo e afetivo dos sujeitos, se constituindo assim, em uma atividade universal, com características singulares que permitem a ressignificação de diferentes conceitos" (ALVES, 2012, p. 4).

Para Huizinga (2000), o jogo apresenta características essenciais que o define, em resumo, como uma atividade livre (ou voluntária), executada em limites espaciais e temporais próprios, segundo regras próprias a serem realizadas, seguidos de um sentimento de tensão e de alegria e de uma consciência de evasão temporária da realidade. De acordo com o autor, essa definição abarca jogos de diversas naturezas, como de força, sorte, adivinhação e agilidade, realizados entre animais, crianças e adultos (HUIZINGA, 2000).

Com o tempo, os jogos passaram a ser compreendidos como atividades de entretenimento pela sociedade em geral. Alves diz ainda que "para muitos, há apenas lazer, o que, muitas vezes, é visto como perda de tempo." (ALVES, 2012, p.4). Por esse motivo, muitos professores ainda hesitam em utilizar o jogo em sala de aula.

Se o jogo faz parte contexto histórico e cultural da humanidade, é relevante inseri-lo também nos cenários educativos (FERNANDES; RIBEIRO, 2018).

Diante do exposto, o presente trabalho tem como objetivo apresentar um jogo elaborado a partir de uma tese sobre os conhecimentos da comunidade de Pedra Branca (COSTA-NETO, 2003) e o científico escolar sobre os insetos, a fim de que essa proposição didática auxilie e valorize no diálogo intercultural no ensino de Biologia das escolas situadas no povoado e no seu entorno.

Cabe ressaltar que esse estudo é resultado do trabalho desenvolvido em uma disciplina ofertada pelo Programa de Pós-Graduação em Ensino, Filosofia e História das Ciências da Universidade Federal da Bahia e Universidade Estadual de Feira de Santana, uma vez que um dos objetivos era a elaboração e apresentação de materiais didáticos e estratégias de ensino de Ciências baseadas no diálogo intercultural a partir de pesquisas da Etnobiologia já realizadas.

\section{MATERIAIS E MÉTODOS}

O trabalho proposto está embasado em teóricos da pesquisa qualitativa em educação (BOGDAN; BIRKLEN, 1994; LÜDKE; ANDRÉ, 2015) e da pesquisa bibliográfica (GIL, 2002, RAMOS; FARIA; FARIA, 2014).

\section{Levantamento da tese e dos livros didáticos}

O levantamento da tese foi efetuado junto à base de dados do Banco de Teses e Dissertações da Coordenadoria de Aperfeiçoamento de Pessoal de Nível Superior (CAPES). Essa base tem como propósitos reunir e disponibilizar o acesso online às teses e dissertações defendidas junto aos programas de Pós-Graduação do Brasil.

A busca foi realizada manualmente no período de fevereiro de 2018 e atualizada em junho de 2019, utilizando individualmente as palavras-chave: "etnobiologia", "etnoecologia", "etnozoologia", "etnobotânica" e "etnoentomologia". Em seguida, foi elaborada a tabulação dos dados no software Microsoft Office Excel, considerando as seguintes informações a respeito dos trabalhos: título, autor ou autora, ano da defesa, programa de pós-graduação e instituição de ensino.

Para selecionar a pesquisa, foram estabelecidos os seguintes critérios de inclusão: (a) estudos publicados no lapso temporal de 2003 a 2017; (b) apresentar as palavras-chaves "etnobiologia", "etnoecologia", "etnozoologia", "etnobotânica" e "etnoentomologia" no título; (c) pesquisas realizadas no estado da Bahia; (d) envolver comunidades de agricultores e agricultoras.

Como critérios de exclusão, foram eliminadas as pesquisas: (a) realizadas fora do lapso temporal determinado; (b) com ausência das palavras-chave no título; (c) duplicadas; (d) realizadas em outros estados ou de abrangência regional; (e) envolvendo comunidades não agrícolas.

A seguir, a Figura 1 apresenta o fluxograma com as etapas de identificação, critérios de eliminação, seleção e o resultado. 


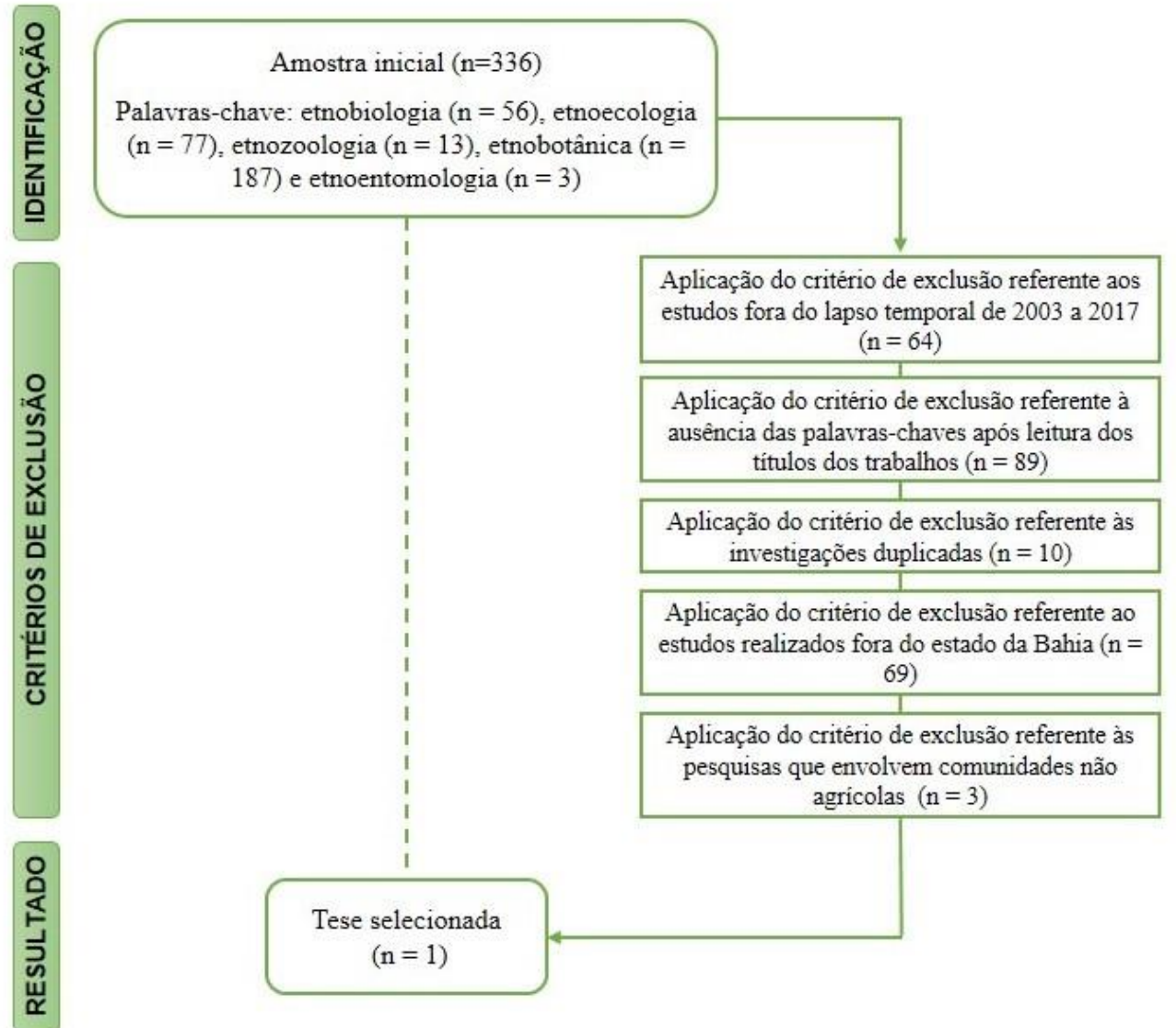

Figura 1: Fluxograma com as etapas de identificação, critérios de eliminação seleção e o resultado da tese selecionada.

Conforme a Figura 1, inicialmente foram localizadas 336 teses. Do total, 64 foram excluídas por serem datadas de antes de 2003 e depois de 2017; 189 por não conterem no título os descritores estabelecidos; 10 por serem duplicadas; 69 por terem sido realizadas em outros estados ou de abrangência regional; 3 por envolver comunidades não agrícolas.

Ao final da pesquisa, a tese eleita foi a intitulada "Etnoentomologia no povoado de Pedra Branca, município de Santa Terezinha, Bahia. Um estudo de caso das interações seres humanos/insetos", de autoria do professor e doutor Eraldo Medeiros Costa Neto, publicada em 2003.

Após essa etapa, foi efetivada a busca pelos livros didáticos de Biologia para a construção do jogo. Como o estudo refere-se ao conhecimento da comunidade de Pedra Branca sobre os insetos, a pesquisa teve como objetivo buscar livros didáticos de Biologia do segundo ano do Ensino Médio, uma vez que o conteúdo sobre os insetos é trabalhado nessa série escolar.

A escolha dos livros foi efetuada a partir das obras contidas no Guia do Livro Didático do Ensino Médio (BRASIL, 2017), aprovadas no âmbito do Programa Nacional do Livro Didático, visto que eles são recomendados para aquisição e utilização nas escolas públicas de educação básica. Em seguida, foi verificada a disponibilidade dessas obras na internet na versão online e gratuita para download. Em decorrência disso, as obras selecionadas foram "Biologia dos Organismos" (AMABIS; MARTHO, 2004, 2016), "Biologia Hoje" (LINHARES; GEWANDSZNAJDER; PACCA, 2016) e "Bio" (LOPES, 2004; LOPES; ROSSO, 2016).

\section{Leitura e seleção dos dados}

De início, foram realizadas a leitura e seleção dos dados da tese. O estudo de Costa-Neto (2003) visou investigar o conhecimento etnoentomológico junto aos moradores do povoado de Pedra Branca, considerando as dimensões afetivas, cognitivas e comportamentais da complexa relação da comunidade com os insetos. Sendo assim, o autor aborda sobre essas dimensões nos resultados e discussão da pesquisa.

Na dimensão afetiva, Costa-Neto registrou os seguintes tópicos: a percepção e a construção 
êmica do domínio etnozoológico "inseto"; os impactos negativos da ação direta dos insetos sobre a saúde humana; as etnoespécies consideradas pragas; e o significado semiótico dos insetos. No tocante à dimensão cognitiva, observou os seguintes pontos: etnoontogenia e biotransformações; e a história natural de grupos de insetos culturalmente importantes. Por fim, a dimensão comportamental tratou sobre usos medicinal, alimentar, lúdico, estético-decorativo, ritualístico, entre outros.

Para a construção do recurso, foram selecionados alguns dados às dimensões afetiva e comportamental. A respeito da dimensão afetiva, foram selecionadas as informações acerca dos impactos negativos da ação direta dos insetos sobre a saúde humana e das etnoespécies tidas como daninhas às plantações locais. Quanto à dimensão comportamental, os dados pertinentes ao uso medicinal e alimentar. Essas dimensões foram escolhidas porque revelam sensações e comportamentos positivos e negativos a partir da interação dos entrevistados com relação aos insetos. Todas essas informações foram tabuladas em uma planilha do software da Microsoft Office Excel e agrupadas em categorias: principais representantes dos insetos, impactos negativos da ação direta dos insetos sobre a saúde humana e/ou as etnoespécies consideradas pragas e uso medicinal e/ou alimentício dos insetos.

Após a leitura e seleção de dados da tese, foi executada a leitura dos três livros didáticos referente ao conteúdo sobre os insetos e, em seguida, foram tabulados em uma planilha os dados sobre os principais representantes dos insetos, suas ordens e suas principais características.

A partir das planilhas, foi construída a Tabela 1. Os critérios estabelecidos para a sua construção foram: (a) identificar os representantes dos insetos comuns às informações da tese e dos livros didáticos; (b) selecionar trechos ou falas dos entrevistados contidas nas dimensões referentes a cada representante dos insetos; (c) selecionar informações sobre a ordem de cada inseto e suas principais características.

Tabela 1 - Principais representantes dos insetos, dados da tese e dos livros didáticos.

\begin{tabular}{|c|c|c|c|}
\hline \multirow[b]{3}{*}{$\begin{array}{l}\text { Principais } \\
\text { represen- } \\
\text { tantes dos } \\
\text { insetos }\end{array}$} & \multicolumn{2}{|c|}{$\begin{array}{c}\text { Dados da Tese } \\
(\text { COSTA-NETO, 2003) }\end{array}$} & \multirow{3}{*}{$\begin{array}{c}\text { Dados dos livros } \\
\text { didáticos } \\
\text { (AMABIS; MARTHO; } \\
\text { 2004; 2016; LOPES; } \\
\text { 2004; LINHARES; } \\
\text { GEWANDSZNAJDER; } \\
\text { PACCA, 2016; LOPES; } \\
\text { ROSSO, 2016) } \\
\end{array}$} \\
\hline & Dimensão Afetiva & Dimensão Comportamental & \\
\hline & $\begin{array}{c}\text { Impactos negativos da ação direta } \\
\text { dos insetos sobre a saúde humana } \\
\text { e/ou as etnoespécies consideradas } \\
\text { pragas }\end{array}$ & $\begin{array}{l}\text { Uso medicinal e/ou alimentício dos } \\
\text { insetos }\end{array}$ & \\
\hline 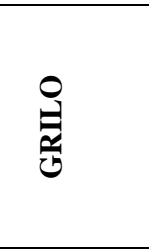 & $\begin{array}{l}\text { "A roça de jiló (Solanum gilo Raddi, } \\
\text { Solanaceae) é atacada pelo grilo." } \\
\text { (p. } 75)\end{array}$ & $\begin{array}{l}\text { "Os entrevistados citaram o chá de grilos } \\
\text { para o tratamento da asma e também de } \\
\text { pedra nos rins, visto que foi considerado } \\
\text { como um diurético eficiente." (p. 164) }\end{array}$ & \multirow{3}{*}{$\begin{array}{l}\text { Ordem Orthoptera: } \\
\text { - a maioria com dois } \\
\text { pares de asas, sendo o } \\
\text { par anterior mais rígido } \\
\text { do que o posterior; } \\
\text { - algumas espécie } \\
\text { possuem corpo achatado } \\
\text { dorsoventralmente; } \\
\text { - algumas espécies são } \\
\text { herbívoras e outras } \\
\text { onívoras. }\end{array}$} \\
\hline 足 & $\begin{array}{l}\text { "Gafanhoto ataca muito } \quad \text { no } \\
\text { parreiral (Seu A., } 73 \text { anos)". (p. 69) }\end{array}$ & & \\
\hline 芯 & $\begin{array}{l}\text { "[...] a barata, que estraga tudo } \\
\text { (Dona E., } 56 \text { anos)." (p. 66) }\end{array}$ & $\begin{array}{l}\text { "Com os fragmentos de uma barata } \\
\text { torrada inteira são feitos remédios } \\
\text { prescritos para curar bronquite asmática, } \\
\text { dor de ouvido, embriaguez, asma, } \\
\text { epilepsia, estrepada (ferida feita com } \\
\text { estrepe) e furúnculos (tumores); aos } \\
\text { pedaços, ela é remédio para asma e } \\
\text { cólicas menstruais." (p. 160). }\end{array}$ & \\
\hline
\end{tabular}

1 De acordo com Amabis e Martho (2004), a barata compõe a Ordem Orthoptera. Porém, segundo a literatura científica da área (BRUSCA; BRUSCA, 2007) e a tese de Costa-Neto (2007), o inseto faz parte da Ordem Blattodea. Para o presente trabalho, optou-se por utilizar a informação contida no livro didático, o qual integrou o procedimento da pesquisa. 


\begin{tabular}{|c|c|c|c|}
\hline 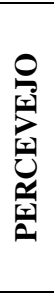 & $\begin{array}{l}\text { "O povo não dormia de noite por } \\
\text { causa das picadas e da coceira } \\
\text { (Dona } \mathrm{R} .,+30 \text { anos)". (p. } 69)\end{array}$ & - & $\begin{array}{l}\text { Ordem Hemiptera: } \\
\text { - a maioria com dois } \\
\text { pares de asa, sendo o par } \\
\text { anterior mais rígido na } \\
\text { base e membranoso na } \\
\text { extremidade; } \\
\text { - são parasitas externos } \\
\text { de plantas. }\end{array}$ \\
\hline 苍 & $\begin{array}{l}\text { "Pulgão... dão pragas da } \\
\text { bananeira-prata (Seu F., } 40 \text { anos)". } \\
\text { (p. 71) }\end{array}$ & ----- & \multirow[t]{2}{*}{$\begin{array}{l}\text { Ordem Homoptera: } \\
\text { - a maioria com dois } \\
\text { pares de asas e algumas } \\
\text { espécies sem asas; } \\
\text { - alimentam-se de seiva } \\
\text { vegetal, parasitando } \\
\text { plantas. }\end{array}$} \\
\hline 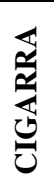 & $\begin{array}{l}\text { "Se ela urinar nas vistas da pessoa, } \\
\text { cega. Ela solta aquela água. Dá } \\
\text { aquela seringada (Dona M., } 59 \\
\text { anos)." (p. 59) }\end{array}$ & -- & \\
\hline 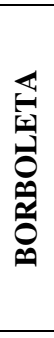 & $\begin{array}{l}\text { "[...] minhas "cinzas" ou "pó" [...] } \\
\text { "Diz que se cair no olho da pessoa } \\
\text { isso aqui cega" (Seu D., + } 70 \text { anos)" } \\
\text { (p. 56-57) } \\
\text { "As mangas deram tudo bichada } \\
\text { esse ano devido a uma borboletinha } \\
\text { branca que solta uma cinza (Dona } \\
\text { E., } 66 \text { anos)". (p. } 73 \text { ) }\end{array}$ & & \multirow[t]{2}{*}{$\begin{array}{l}\text { Ordem Lepidoptera: } \\
\text { - possuem dois pares de } \\
\text { asas grandes e } \\
\text { membranosas; } \\
\text { - as larvas são } \\
\text { herbívoras e os adultos } \\
\text { alimentam-se do néctar } \\
\text { das flores. }\end{array}$} \\
\hline 离 & $\begin{array}{l}\text { "Chupa o umbigo das crianças novas } \\
\text { à noite (Dona M., } 59 \text { anos)". (p.58) } \\
\text { "Dá na lavoura de fumo (Seu F., } 40 \\
\text { anos)". (p. 75) }\end{array}$ & & \\
\hline 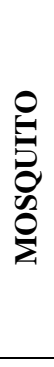 & $\begin{array}{l}\text { "Na mandioca dá uns mosquitozinho } \\
\text { alvinho. Ele fica parece que é mel. } \\
\text { Ele é doce (Dona L., + } 60 \text { anos)". } \\
\text { (p.70) }\end{array}$ & & $\begin{array}{l}\text { Ordem Diptera: } \\
\text { - as asas anteriores são } \\
\text { desenvolvidas, finas e } \\
\text { transparente; } \\
\text { - as asas posteriores são } \\
\text { modificadas e atuam } \\
\text { como órgãos de } \\
\text { equilíbrio; } \\
\text { - a alimentação varia de } \\
\text { acordo com a espécie. }\end{array}$ \\
\hline 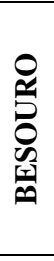 & $\begin{array}{l}\text { "No lugar que ele passa, ele queima } \\
\text { parecendo que foi fogo (Dona E., } 56 \\
\text { anos)." (p. 58) } \\
\text { "só faz serrar o pé de caju (Dona } \\
\text { E., } 66 \text { anos)". (p. 72) }\end{array}$ & & $\begin{array}{l}\text { Ordem Coleoptera: } \\
-\quad \text { pares de asas } \\
\text { posteriores } \\
\text { membranosas e finas; } \\
\text { - pares de asas anteriores } \\
\text { (élitros), convexas e } \\
\text { duras. }\end{array}$ \\
\hline 矛 & $\begin{array}{l}\text { "Um homem já morreu picado por } \\
\text { abelhas (Dona M., } 55 \text { anos)." (p. 48) }\end{array}$ & $\begin{array}{l}\text { "Os méis silvestres são os recursos mais } \\
\text { amplamenter consumidos, } \\
\text { principalmente aqueles produzidos pelas } \\
\text { abelhas sem ferrão. Muitas vezes, o mel } \\
\text { é consumido como remédio: } O \text { mel da } \\
\text { uruçu é bom pra um bocado de remédio } \\
\text { (Seu J., + } 70 \text { anos)." (p. 171) }\end{array}$ & $\begin{array}{l}\text { Ordem Hymenoptera: } \\
\text { - algumas espécies } \\
\text { possuem dois pares de } \\
\text { asas finas e } \\
\text { membranosas; } \\
\text { - algumas espécies não } \\
\text { possuem asas; }\end{array}$ \\
\hline
\end{tabular}




\begin{tabular}{|c|c|c|c|}
\hline 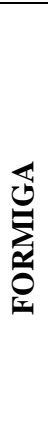 & $\begin{array}{l}\text { "Formiga é praga da uva (Seu F., } 40 \\
\text { anos)". (p.73) } \\
\text { "Formiga (Corta o café, Dona T., + } \\
60 \text { anos)." (p.73) }\end{array}$ & $\begin{array}{l}\text { "Das tanajuras, os usuários extraem os } \\
\text { abdomes, torrando-os ou fritando-os } \\
\text { geralmente em sua própria gordura. Faz- } \\
\text { se, então, uma farofa com ou sem sal. } \\
\text { Crianças são as principais coletoras, } \\
\text { realizando a tarefa enquanto entoam o } \\
\text { refrão Cai, cai tanajura, na panela de (da) } \\
\text { gordura. Aqui, tem ocasião aqui de } \\
\text { juntar mais de dez menino aqui, tudo } \\
\text { correndo, tudo enchendo as latinha tudo } \\
\text { de bundinha, disse Seu A., } 73 \text { anos." (p. } \\
\text { 172) }\end{array}$ & $\begin{array}{l}\text { - algumas espécies } \\
\text { possuem alto grau de } \\
\text { organização social. }\end{array}$ \\
\hline 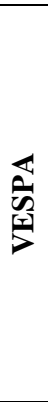 & $\begin{array}{l}\text { "[...] íngua, dor de cabeça, "Dá febre } \\
\text { danada” (Dona E., } 82 \text { anos)." (p. } \\
49)\end{array}$ & $\begin{array}{l}\text { "[...] os ninhos do marimbondo- } \\
\text { sussubera e do marimbondo-escopo são } \\
\text { usados no tratamento da parotidite, } \\
\text { também conhecida como caxumba ou } \\
\text { papeira: De primeiro, eu me lembro, meu } \\
\text { pai, quando a gente tinha aqueles } \\
\text { negócio de caxumba, aí fazia. Ele } \\
\text { pegava, fazia aquela lama e passava no } \\
\text { rosto da gente. E curava. No outro dia } \\
\text { amanhecia tudo desinchado (Dona E., } \\
66 \text { anos). " (p. } 165)\end{array}$ & \\
\hline 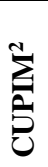 & $\begin{array}{l}\text { "[...] o cupim, que destrói tudo. } \\
\text { Roupa, madeira, tudo (Seu A. J., } 74 \\
\text { anos)". (p.66) }\end{array}$ & $\begin{array}{l}\text { "Em Pedra Branca, partes de cupinzeiros } \\
\text { das etnoespécies cupim e cupim-roxo } \\
\text { são receitados para tratar gripe e umbigo } \\
\text { grande de crianças." (p. 65) }\end{array}$ & \\
\hline
\end{tabular}

\section{RESULTADO E DISCUSSÃO}

\section{O Jogo "Conhecendo os insetos"}

O jogo proposto no presente estudo foi intitulado "Conhecendo os insetos", tendo sido inspirado no clássico jogo das dicas chamado Perfil da empresa GROW.

A inserção das informações da referida tabela na elaboração do jogo possibilita o diálogo sobre: as ordens mais conhecidas que subdividem a classe Insecta; as principais características dessas ordens; os principais insetos de cada Ordem; as relações ecológicas entre esses animais, os seres humanos e as plantas; os benefícios e malefícios causados ao homem; a relevância ecológica e econômica; a importância para fins medicinais e alimentares.

Pelo fato de envolver o conteúdo citado, o jogo é composto por vinte e três cartas. Cada carta possui duas dicas sobre o perfil do inseto em questão (Tabela 2). A primeira dica foi elaborada a partir do conhecimento científico escolar das obras consultadas (AMABIS; MARTHO, 2016; LINHARES; GEWANDSZNAJDER; PACCA, 2016; LOPES; ROSSO, 2016). A segunda dica foi constituída por trechos da fala de um participante ou do conteúdo da tese sobre os insetos (COSTA-NETO, 2003). É importante destacar que a incorporação das dicas tem os propósitos de complementar informações referentes ao inseto a ser descoberto pelos alunos e de valorizar, reconhecer e resgatar o conhecimento etnoentomológico como parte importante da identidade e da visão de mundo dos alunos. Além das dicas, a carta possui a respectiva resposta acerca do perfil do inseto (Figura 2).

As cartas podem ser confeccionadas através da impressão das informações em papel cartão e revestidas com um papel adesivo transparente para aumentar sua durabilidade. Convém mencionar que o layout das cartas é original e foi elaborado pela primeira autora do presente trabalho.

\footnotetext{
2 Tal como ocorre com a barata, de acordo com Amabis e Martho (2004), o cupim compõe a Ordem Hymenoptera. Entretanto, segundo a literatura científica da área (BRUSCA; BRUSCA, 2007) e a tese de Costa-Neto (2007), o inseto faz parte da Ordem Isoptera. Novamente, para o presente trabalho, optou-se por utilizar a informação contida no livro didático.
} 
Tabela 2- Números de cartas com as dicas e as respectivas respostas.

\begin{tabular}{|c|c|}
\hline $\begin{array}{l}\text { Número de } \\
\text { Cartas }\end{array}$ & Dicas e respostas das cartas. \\
\hline 1 & $\begin{array}{l}\text { Dica 1: Sou uma espécie com alto grau de organização social. } \\
\text { Dica 2: Posso causar danos a "[...] Roupa, madeira, tudo". } \\
\text { Resposta: Cupins. }\end{array}$ \\
\hline 2 & $\begin{array}{l}\text { Dica 1: Não possuo asas. } \\
\text { Dica 2: A minha casa é matéria-prima para a produção de remédios para o tratamento de gripe } \\
\text { e umbigo grande de crianças. } \\
\text { Resposta: Cupins. }\end{array}$ \\
\hline 3 & $\begin{array}{l}\text { Dica 1: Sou um inseto onívoro. } \\
\text { Dica 2: Sou praga do cultivo do jiló. } \\
\text { Resposta: Grilo. }\end{array}$ \\
\hline 4 & $\begin{array}{l}\text { Dica 1: Sou da Ordem Orthoptera. } \\
\text { Dica 2: Sou utilizado na produção de chá usado para o tratamento de asma e de pedra nos rins } \\
\text { e como um diurético eficiente. } \\
\text { Resposta: Grilo. }\end{array}$ \\
\hline 5 & $\begin{array}{l}\text { Dica 1: Sou da Ordem Orthoptera. } \\
\text { Dica 2: Sou utilizada na produção de remédios para curar bronquite asmática, dor de ouvido, } \\
\text { embriaguez, asma, epilepsia, estrepada e furúnculos. } \\
\text { Resposta: Barata. }\end{array}$ \\
\hline 6 & $\begin{array}{l}\text { Dica 1: Possuo asas posteriores modificadas, que me ajudam no equilíbrio quando estou } \\
\text { voando. } \\
\text { Dica 2: "Sou uma das pragas da mandioca, "Na mandioca dá uns? alvinho". } \\
\text { Resposta: Mosquito. }\end{array}$ \\
\hline 7 & $\begin{array}{l}\text { Dica 1: Não possuo asas. } \\
\text { Dica 2: Meu abdômen é arrancado para ser consumido torrado ou frito "[...] tem ocasião aqui } \\
\text { de juntar mais de dez menino aqui, tudo correndo, tudo enchendo as latinha tudo de } \\
\text { bundinha". } \\
\text { Resposta: Formiga. }\end{array}$ \\
\hline 8 & $\begin{array}{l}\text { Dica 1: Sou uma espécie com alto grau de organização social. } \\
\text { Dica 2: Sou praga dos cultivos da uva e do café. } \\
\text { Resposta: Formiga. }\end{array}$ \\
\hline 9 & $\begin{array}{l}\text { Dica 1: Sou uma espécie com alto grau de organização social. } \\
\text { Dica 2: "Um homem já morreu picado por" um enxame. } \\
\text { Resposta: Abelhas. }\end{array}$ \\
\hline 10 & $\begin{array}{l}\text { Dica 1: Possuo dois pares de asas finas e membranosas. } \\
\text { Dica 2: "O mel da? é bom pra um bocado de remédio". } \\
\text { Resposta: Abelha. }\end{array}$ \\
\hline 11 & $\begin{array}{l}\text { Dica 1: Sou uma espécie com alto grau de organização social. } \\
\text { Dica 2: Meus ninhos são utilizados como matéria-prima no tratamento de doenças como } \\
\text { caxumba e papeira. "De primeiro, eu me lembro, meu pai, quando a gente tinha aqueles } \\
\text { negócio de caxumba, aí fazia. Ele pegava, fazia aquela lama e passava no rosto da gente. E } \\
\text { curava. No outro dia amanhecia tudo desinchado". } \\
\text { Resposta: Vespa ou Maribondo (nome popular) }\end{array}$ \\
\hline 12 & $\begin{array}{l}\text { Dica 1: Sou da Ordem Hymenoptera. } \\
\text { Dica 2: Minha mordida "dá febre danada", íngua e dor de cabeça. } \\
\text { Resposta: Vespa ou Maribondo (nome popular) }\end{array}$ \\
\hline 13 & $\begin{array}{l}\text { Dica 1: Sou da Ordem Orthoptera. } \\
\text { Dica 2: Sou praga que "[...] ataca muito no parreiral". } \\
\text { Resposta: Gafanhoto. }\end{array}$ \\
\hline 14 & $\begin{array}{l}\text { Dica 1: Possuo dois pares de asas, as posteriores finas e membranosas, alojadas sobre as asas } \\
\text { posteriores (élitros), convexas e duras. } \\
\text { Dica 2: Sou uma praga que "só faz serrar o pé de caju". } \\
\text { Resposta: Besouro. }\end{array}$ \\
\hline 15 & $\begin{array}{l}\text { Dica 1: Sou da Ordem Coleoptera. } \\
\text { Dica 2: Posso causar uma sensação de ardência nos seres humanos ao secretar um líquido que } \\
\text { "Queima que tira a pele". } \\
\text { Resposta: Besouro ou Potó (nome popular). }\end{array}$ \\
\hline 16 & $\begin{array}{l}\text { Dica 1: Sou da Ordem Lepidoptera } \\
\text { Dica 2: Minhas "cinzas" ou "pó" "Diz que se cair no olho da pessoa isso aqui cega". } \\
\text { Resposta: Borboleta ou Mariposa }\end{array}$ \\
\hline 17 & $\begin{array}{l}\text { Dica 1: Possuo dois pares de asas grandes e membranosas. } \\
\text { Dica 2: "As mangas deram tudo bichada esse ano devido a uma ? ... que solta uma cinza". } \\
\text { Resposta: Borboleta. }\end{array}$ \\
\hline
\end{tabular}




\begin{tabular}{l|l} 
& $\begin{array}{l}\text { Dica 1: Possuo dois pares de asas grandes e membranosas. } \\
\text { Dica 2: Sou uma das pragas que "Dá na lavoura do fumo". } \\
\text { Resposta: Mariposa. }\end{array}$ \\
\hline 18 & $\begin{array}{l}\text { Dica 1: Sou da Ordem Homoptera. } \\
\text { Dica 2: "Se ela urinar nas vistas da pessoa, cega". } \\
\text { Resposta: Cigarra. }\end{array}$ \\
\hline \multirow{2}{*}{20} & $\begin{array}{l}\text { Dica 1: Sou da Ordem Homoptera. } \\
\text { Dica 2: Sou uma das "[...] pragas da bananeira-prata". } \\
\text { Resposta: Pulgão. }\end{array}$ \\
\hline \multirow{2}{*}{22} & $\begin{array}{l}\text { Dica 1: Sou da ordem Hemiptera. } \\
\text { Dica 2: "O povo não dormia de noite por causa das picadas e da coceira. } \\
\text { Resposta: Percevejo }\end{array}$ \\
\hline \multirow{2}{*}{23} & $\begin{array}{l}\text { Dica 1: Possuo corpo achatado dorsoventralmente. } \\
\text { Dica 2: Sou um inseto que "estraga tudo", causando danos a bens materiais. } \\
\text { Resposta: Barata. }\end{array}$ \\
\hline $\begin{array}{l}\text { Dica 1: Sou herbívora na fase de larva, mas sugo o néctar das flores na fase adulta. } \\
\text { Dica 2: Dizem que chupo "[...] o umbigo das crianças novas à noite". } \\
\text { Resposta: Mariposa. }\end{array}$ \\
\hline
\end{tabular}

\section{Aplicação e regras do Jogo}

O jogo pode ser aplicado em duas aulas seguidas de Biologia, com duração de cinquenta minutos cada, nas turmas do $2^{\circ}$ ano do Ensino Médio. Inicialmente, a proposta deve ser aplicada nas escolas de Pedra Branca e do seu entorno, visto que as informações contidas nele referem-se a esse contexto. Se aplicada em outra localidade, é relevante que seja reelaborado pelo professor com informações etnoentomológicas do contexto correspondente.

Antes de ser aplicado, é importante que o professor já tenha ministrado a aula do conteúdo, pois isso ajudará o aluno a relacionar o conteúdo aprendido com o conhecimento cultural que possui para descobrir o perfil do inseto.

Para iniciar o jogo, recomenda-se que o professor apresente seu propósito, divida a turma em dois ou quatro grupos e oriente que cada grupo deve ter um representante. Depois, deve ler as regras (Figura 3). Cabe ao professor conduzir o jogo e atentar-se ao surgimento de possíveis confusões ou dúvidas referentes ao conteúdo. Caso isso ocorra, deve criar espaços oportunos para que os alunos tenham a chance de expor seus entendimentos e dúvidas sobre o conteúdo tratado, após o término.

Posteriormente, é importante que o professor crie um momento para que os alunos possam expor e avaliar a proposta em si, a relevância para a sua aprendizagem e de que forma pode ser melhorada.

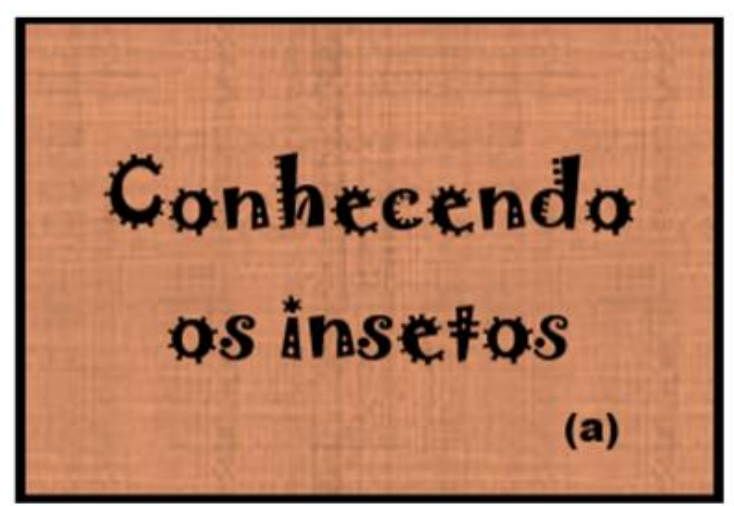

\section{Quem sou eu?}

Dica 1: Sou uma espécie com alto grau de organização social,

Dica 2: Posso causar danos a "[...] Roupa, madeira, tudo" (fala do entrevistado COSTA-NETO, 2003, p.66).

Figura 2: Modelo da carta do jogo "Conhecendo os insetos". (a) A frente da carta. (b) O verso da carta. 


REGRAS DO JOGO "CONHECENDO OS INSETOS"
Como jogar:
1. Após os grupos estarem formados, o mediador deve embaralhar as cartas e, em
seguida, solicitar ao representante do grupo 1 que escolha uma carta.
2. Ao escolher a carta, o mediador deverá ler as duas dicas contidas nas cartas.
3. O grupo tem o tempo de 2 minutos para responder cada carta.
4. Se grupo responder corretamente, o grupo pontua 10 pontos. Caso isso não ocorra, o
grupo 2 tem a chance de responder. Se acertar pontua 5 pontos, se errar a carta é
descartada.
5. Depois disso, a rodada é retomada e o representante do grupo 2 deve escolher uma
carta. A regra anterior deve ser aplicada novamente.
6. O jogo segue essa dinâmica até que todas as cartas acabem.
7. Vence o jogo o grupo que pontuar mais pontos.

Figura 3: Regras do jogo "Conhecendo os insetos".

\section{CONSIDERAÇÕES FINAIS}

Um recurso didático que leve em consideração o conhecimento científico escolar e o conhecimento tradicional dos alunos pode ser uma estratégia para evitar o conflito entre essas culturas e, ao mesmo tempo, ampliar e resgatar os conhecimentos e suas visões de mundo. Além disso, pode propiciar ao professor uma melhor compreensão das culturas existentes na sala de aula, além de despertá-lo para uma reflexão sobre a sua prática docente, o que resultaria em uma prática mais sensível à diversidade cultural.

O uso do jogo como uma proposta didática, pode conjugar diversas finalidades, como: motivar o aluno a expressar sua opinião e agregar conhecimento (BRITO et al.; 2015); incentivá-lo a tirar dúvidas correlatas ao tema e também a buscar novas informações (KRASILCHIK, 2008); avaliar o conhecimento sobre determinado conteúdo; complementar possíveis lacunas sobre determinado tema ou conteúdo abordado no processo de ensino e aprendizagem (MARTINS; BRAGA, 2015); instigar a participação na sala de aula.

O jogo "Conhecendo os insetos" é uma proposta que precisa ser aplicada, inicialmente, nas escolas da própria comunidade de Pedra Branca e do seu entorno, com os objetivos de validá-la e aperfeiçoá-la a partir das sugestões dos alunos e do professor. Apesar do limite contextual de sua aplicação, o jogo pode servir de motivação para que os professores reconstruam a proposta a partir da investigação das informações sobre os insetos do contexto em que estão inserido ou elaborem novas propostas com outros temas e conhecimentos culturais.

\section{AGRADECIMENTOS}

À Fundação de Amparo à Pesquisa do Estado da Bahia, pela concessão da bolsa de doutorado da primeira autora, que é discente da Pós-Graduação em Ensino, Filosofia e História das Ciências da Universidade Federal da Bahia e da Universidade Estadual de Feira de Santana.

\section{REFERÊNCIAS}

AIKENHEAD, G. S. Science communication with the public: a cross-cultural event. In: BRYANT, C.; GORE, M.; STOCKLMAYER, S. (Eds.). Science communication in theory and practice. Amsterdam: Kluwer, 2001, p. 23-45.

ALBUQUERQUE, U. P; ALVES, A. G. C. O que é etnobiologia? In: ALBUQUERQUE, U. P. (Org.). Introdução à etnobiologia, Recife: NUPEA, 2014, p. 17-22.

ALVES, L. Videojogos e aprendizagem: mapeando percursos. In: CARVALHO, A. A. (Org.). Aprender na era digital - jogos e mobile learning. Santo Tirso: De Facto Editores, v. 01, 2012, p. 11-28.

AMABIS, J. M.; MARTHO, G.R. Biologia dos Organismos. São Paulo: Moderna, 2004, 685 p.

AMABIS, J. M.; MARTHO, G.R. Biologia dos Organismos. São Paulo: Moderna, 2016, 352 p.

BAPTISTA, G. C. S. A contribuição da etnobiologia para o ensino e a aprendizagem de ciências: estudo de caso em uma escola pública do estado da Bahia. 2007. (Mestrado em Ensino, Filosofia e História das Ciências) 
- Universidade Federal da Bahia, Universidade Estadual de Feira de Santana, Salvador, 2007.

BAPTISTA, G. C. S. Importância da demarcação de saberes no ensino de ciências para as sociedades tradicionais. Ciência \& Educação, v. 16, n. 3, 2010, p. 679-694.

BAPTISTA, G. C. S. Do cientificismo ao diálogo intercultural na formação do professor e ensino de ciências. Interacções, Lisboa, v. 10, n. 31, 2014, p. 28-53.

BAPTISTA, G. C. S. Contribuições da etnobiologia para o ensino aprendizagem de ciências. Curitiba: Appris, 2015, 175 p.

BAPTISTA, G. C. S.; DA SILVA SANTOS, R.; COBERN, W. W. Perspectives on the Origins of Life in Science Textbooks from a Christian Publisher: Implications for Teaching Science. International Journal of Science and Mathematics Education, v. 14, n. 2, p. 309-326, 2016.

BOGDAN, R.; BIRKLEN, S. Investigação qualitativa em educação: uma introdução à teoria e aos métodos.

Porto: Porto Editora, 1994, 336 p.

BRASIL. Ministério da Educação. PNLD 2018: biologia - guia de livros didáticos - Ensino Médio. Brasília,

DF: Ministério da Educação, Secretária de Educação Básica, 2017. 92 p.

BRITO, F. M. et al. Dinamizando e motivando o aprendizado escolar por meio dos jogos pedagógicos. Holos, v. 2, 2015, p. 264-272.

BRUSCA, R. C.; BRUSCA, G. J. Invertebrados. Rio de Janeiro: Editora Guanabara Kooghan, 2007.

COBERN, W. W. Constructivism and non-western science education research. International Journal of Science Education, Routledge, v. 4, n. 3, 1996, p. 287-302.

COBERN, W. W.; LOVING, C. C. Defining "science" in a multicultural world: implications for science education. Science Education, New York, v. 85, n. 1, 2001, p. 50-67.

COSTA-NETO, E. M. Etnoentomologia no Povoado de Pedra Branca, município de Santa Terezinha,

Bahia. Um estudo de caso das interações seres humanos/insetos. 2003. Tese (Doutorado em Ecologia e Recursos Naturais) - Universidade Federal de São Carlos, São Carlos, 2003.

DE ANDRADE COSTA, R. G. Os saberes populares da etnociência no ensino das ciências naturais: uma proposta didática para aprendizagem significativa. Revista Didática Sistêmica, v. 8, p. 162-172, 2008.

DIEGUES, A. C. Os Saberes Tradicionais e a Biodiversidade no Brasil. São Paulo: Universidade de

São Paulo, 2000, 211 p.

FERNANDES, C. W. R; RIBEIRO, E. L. P. Games, gamificação e o cenário educacional brasileiro. CIET:

EnPED, 2018, p. 1-22. Disponível em: http://cietenped.ufscar.br/submissao/index.php/2018/article/view/344.

Acessado em: 8 jan. 2019.

HUIZINGA, J. Homo ludens: O jogo como elemento da cultura. São Paulo: Perspectiva, 2000, 162 p.

GIL, Antônio Carlos. Como elaborar projetos de pesquisa. São Paulo: Atlas, 2002.

KRASILCHIK, M. Prática de ensino de biologia. São Paulo: Editora da Universidade de São Paulo, 2008, $197 \mathrm{p}$.

LINHARES, S.; GEWANDSZNAJDER, F; PACCA, H. Biologia Hoje. São Paulo: Ática, 2014, 384 p.

LOPES, A. R. C. Pluralismo cultural em políticas de currículo nacional. In: MOREIRA, A. F. B. (Org.).

Currículo: políticas e práticas. Campinas: Papirus, 1999. p. 59-80.

LOPES, S. Bio. São Paulo: Saraiva, 2004.

LOPES, S; ROSSO, S. Bio. São Paulo: Saraiva, 2016.

LÜDKE, M.; ANDRÉ, M. E. D. A. Pesquisa em Educação: abordagens qualitativa. Rio de Janeiro: EPU, 2015, 112 p.

MARQUES, J. G. W. Pescando Pescadores. 2. ed. São Paulo: NUPAUB-USP, 2001. 258 p

MARTINS, I.C.P.; BRAGA, P.E.T. Jogo didático como estratégia para o ensino de divisão celular. Essentia, v.16, n.2, jan/jun, 2015, p. 1-21.

MARTINS, K. V. M.; BAPTISTA, G. C. S.; ALMEIDA, R. O. Construindo um recurso didático a partir dos saberes tradicionais: implicações e proposições para o ensino intercultural de biologia. Revista de Ensino de Biologia da associação Brasileira de Ensino de biologia (SBENBio), v. 9, p. 2392-2403, 2016. Disponível em: http://www.sbenbio.org.br/wordpress/wp-content/uploads/renbio-9/pdfs/1935.pdf. Acesso em: 12 dez. 2017.

MIRANDA, F. S.; STADZISZ, P. C. Jogo Digital: definição do termo. In: Simpósio Brasileiro de Jogos e Entreterimento Digital (SBGmaes), 2017, p. 296-299. Disponível em: https://www.researchgate.net/publication/324892358_Jogo_Digital_definicao_do_termo.

NASCIBEM, F. G.; VIVEIRO, A. A. Para além do conhecimento científico: a importância dos saberes populares para o ensino de ciências. Interacções, Lisboa, v. 11, n. 39, 2015, p. 285-295. Disponível em: https://revistas.rcaap.pt/interaccoes/article/view/8738. Acessado em: 8 jan. 2019.

POSEY, D. A. Etnobiologia: teoria e prática. In: RIBEIRO, D. (Ed.). Suma etnológica brasileira. $3 . \quad$ ed. Petrópolis: Vozes, v. 1, 1987, p. 1-15. Disponível ftp://neppi.ucdb.br/pub/cedoc/pdf/ETNOBIOLOGIA.pdf. Acessado em: 05 dez. 2016.

POSNER, G. J. et al. Accommodation of a scientific conception: Toward a theory of conceptual change. Science education, New York, v. 66, n. 2, p. 211-227, 1982.

RAMOS, A.; FARIA, P. M.; FARIA, Á. Revisão sistemática de literatura: contributo para a inovação na investigação em Ciências da Educação. Revista Diálogo Educacional, v. 14, n. 41, 2014, p. 17-36. 
RODRIGUES, C. et al. Uma hipótese curricular para a formação continuada de professores de ciências e de matemática. Ciência \& Educação, v. 16, n. 2, 2010, p. 415-426.

SEPULVEDA, C. A. S. A relação Religião e Ciência na trajetória profissional de alunos protestantes da licenciatura em Ciências Biológicas. 2003. Dissertação (Mestrado em Ensino, Filosofia e História das Ciências) - Universidade Federal da Bahia, Universidade Estadual de Feira de Santana, Salvador, 2003.

SILVA, E. A. O.; BAPTISTA, G. C. S. Un recurso acerca de los hongos para el diálogo intercultural en la enseñanza de biología. Góndola, Enseñanza y Aprendizaje de las Ciencias: Góndola, Enseñanza y Aprendizaje de las Ciencias, v. 12, n. 2, 2017, p. 142-157.

SIQUEIRA, A. B. Etnobotânica no Currículo de Ciências na Educação de Jovens e Adultos. REMEA-Revista Eletrônica do Mestrado em Educação Ambiental, v. 26, 2011, p. 1-16. Disponível em: https://periodicos.furg.br/remea/article/view/3348. Acessado em: 17 mar. 2019.

SIQUEIRA, A. B. Etnobiologia como metodologia no ensino de ciências. In: IV Simpósio sobre Formação de Professores-SIMFOP, Anais [...] Santa Catarina: Unisul, v. 4, 2012, p. 1-7. Disponível em: http://linguagem.unisul.br/paginas/ensino/pos/linguagem/eventos/simfop/artigos_IV\%20sfp/_Andr\%C3\%A9_Si queira.pdf. Acessado em: 17 mar. 2019.

VERDE, A. et al. La Etnobiología como materia transversal en el currículo de educación secundaria. Una experiencia en Castilla La-Mancha (España). ENSAYOS, n. 24, 2009, p. 149-162. 